\title{
Combined Transarterial Chemoembolization and External Beam Radio- therapy in a Patient with Recurrent Huge Hepatocellular Carcinoma after Hepatic Resection
}

\author{
Jesang Yu, Jinhong Jung, Sang Min Yoon \\ Department of Radiation Oncology, Asan Medical Center, University of Ulsan College of Medicine, Seoul, Korea
}

Received Jan. 18, 2020

Revised Feb. 22, 2020

Accepted Feb. 25, 2020
The optimal treatment strategy for unresectable huge hepatocellular carcinoma (HCC) is yet to be established. Non-surgical monotherapy demonstrated insufficient oncologic outcomes in previously reported studies. To improve the clinical outcomes of unresectable huge HCC, combined locoregional treatments can be considered in selected cases. Here, we report a case of 58-year-old male patient who was treated with combined transarterial chemoembolization (TACE) and external beam radiotherapy for recurrent HCC after a previous hepatic resection. After combined TACE and radiotherapy for the intrahepatic lesion, two metastases were diagnosed in the pelvic bones and lung; each lesion was successfully treated with salvage radiotherapy. During the long-term follow-up period (around 8 years 7 months after combined TACE and radiotherapy for the recurrent huge HCC), no definite viable tumors were observed in any of the treated liver, bone, and lung lesions. (J Liver Cancer 2020;20:90-97)

Keywords: Huge; Hepatocellular carcinoma; Therapeutic chemoembolization; Radiotherapy

\section{INTRODUCTION}

Symptoms related with hepatocellular carcinoma (HCC) are usually affected by the location of the tumor along with its size. As the patients with small HCC do not commonly have self-conscious symptoms, around $10 \%$ of patients are diagnosed with huge HCC $(\geq 10 \mathrm{~cm})$ at their initial presentation. ${ }^{1}$ Although surgery has been widely used as a potential curative treatment option, most huge HCC patients showed a poor prognosis in previous reported studies. ${ }^{1-8}$ Moreover, patients with huge HCC are often considered unresectable

\section{Corresponding author : Sang Min Yoon}

Department of Radiation Oncology, Asan Liver Center, Asan Medical Center, University of Ulsan College of Medicine, 88 Olympic-ro 43-gil, Songpa-gu, Seoul 05505, Korea

Tel. +82-2-3010-5615, Fax. +82-2-3010-6950

E-mail;drsmyoon@amc.seoul.kr

https://orcid.org/0000-0002-5138-3051 owing to the difficulty of complete resection or insufficient remnant liver volume. ${ }^{9}$ Therefore, the optimal treatment strategy for unresectable huge HCC has not yet been established. Any single modality, with the exception of hepatic resection, is unable to provide sufficient local tumor control. ${ }^{10-12}$ Combined locoregional treatments can be effective options because of the expected synergistic effects in selected cases. ${ }^{13,14}$ Here, we have presented a case of a patient with recurrent huge HCC who was treated with combined transarterial chemoembolization (TACE) and external beam radiotherapy. Further, we have presented the patient's long-term clinical outcomes. In accordance with the regulations, no Institutional Review Board approval was needed for this report.

\section{CASE REPORT}

A 58-year-old male patient was referred to our hospital in

Copyright $\odot 2020$ by The Korean Liver Cancer Association. All rights reserved.

This is an Open Access article distributed under the terms of the Creative Commons Attribution Non-Commercial License (http://creativecommons.org/licenses/by-nc/4.0/) which permits unrestricted non-commercial use, distribution, and reproduction in any medium, provided the original work is properly cited. 
August 2006 because a regular health examination revealed elevated an alpha-fetoprotein (AFP) level. He had a history of hepatitis B virus infection. The initial laboratory findings were as follows: platelet count $156 \times 10^{3} / \mathrm{L}$, serum albumin $3.8 \mathrm{~g} / \mathrm{dL}$, aspartate transaminase $32 \mathrm{IU} / \mathrm{L}$, alanine transaminase $41 \mathrm{IU} / \mathrm{L}$, alkaline phosphatase $80 \mathrm{IU} / \mathrm{L}$, total bilirubin $0.8 \mathrm{mg} / \mathrm{dL}$, prothrombin time 13.2 seconds, and international normalized ratio 1.08 . The AFP level was 2,160 ng/mL. A contrast-enhanced liver dynamic computed tomography (CT) scan revealed a $3.5 \mathrm{~cm}$ hepatic mass across segments 8 and 4, which had a solid portion on the medial side of the tumor with a non-enhancing cystic portion on the lateral as- pect. Although the enhancement of the solid portion was not strongly observed in the arterial phase, subtle washout and capsule enhancement were observed in the delayed phase. Considering all the findings, this tumor was diagnosed clinically as an HCC. The patient received hepatic resection (central bi-segmentectomy) on October 23, 2006 and the mass was diagnosed as a $4.5 \times 4.3 \times 2.5$-cm, multinodular confluent-type HCC (the Edmondson-Steiner grade 3/3) on pathologic examination. During the regular follow-up period, a recurrent HCC measuring $3 \mathrm{~cm}$ in segment 3 was observed on liver dynamic CT at 4 years after surgery. However, the patient refused further work-up or management at that time.
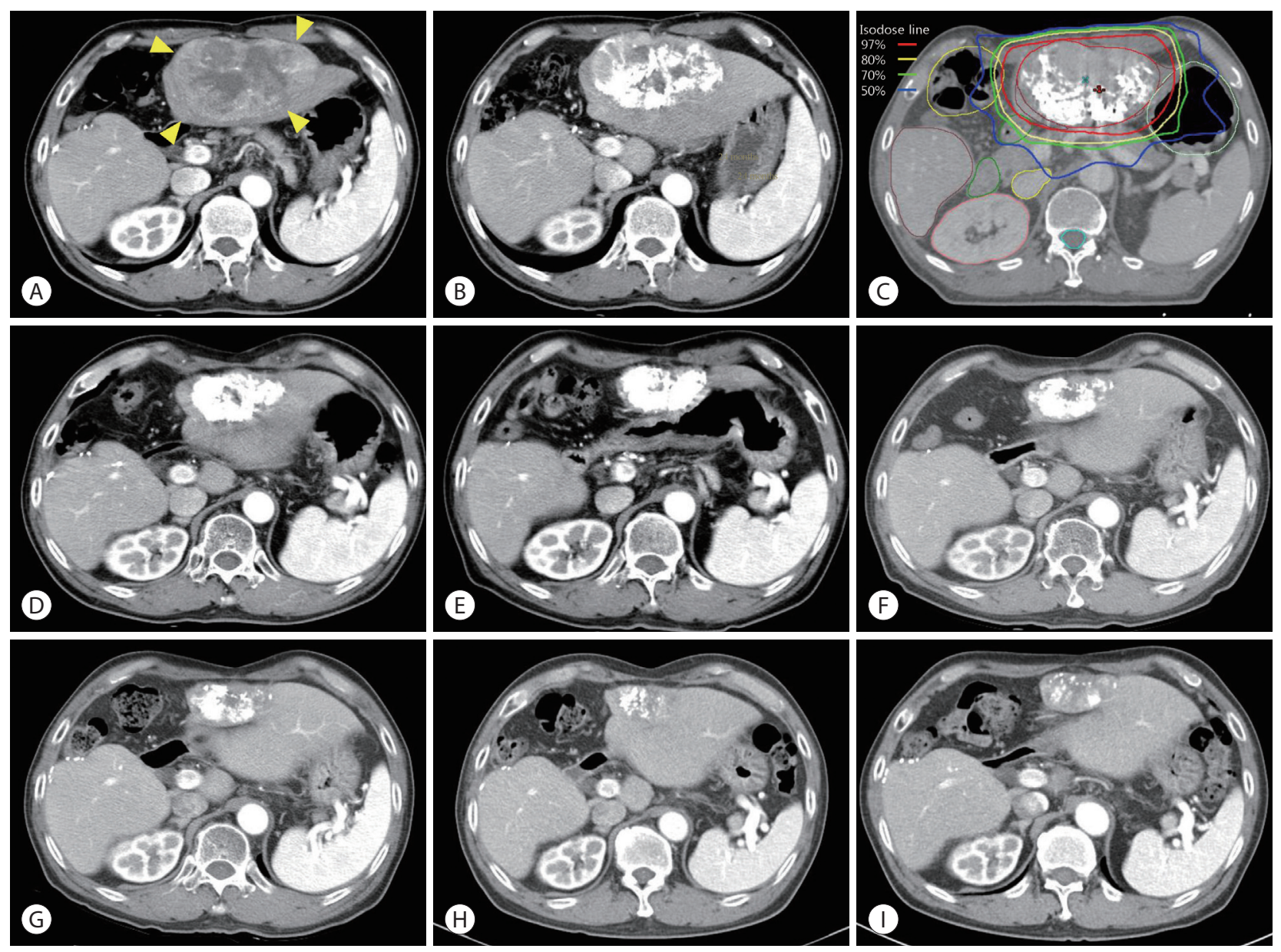

Figure 1. Serial liver dynamic computed tomography $(C T)$ images from the time of recurrence to the last follow-up at 8.6 years. (A) a recurrent hepatocellular carcinoma (HCC) measuring $11 \mathrm{~cm}$ (yellow arrowheads) in segment 3 was observed on the arterial phase. (B) Partial iodized oil uptake in recurrent HCC was observed on the follow-up CT scan 1 month after the first TACE. (C) Iso-dose lines of radiotherapy for the recurrent HCC on the planning CT. Total dose (30 Gy in 12 fractions) was prescribed with $97 \%$ iso-dose line. (D) After TACE (a total of 5 times) and radiotherapy, no definitive viable HCC was observed. Follow-up CT images at 1 year $(\mathrm{E}), 2$ years $(\mathrm{F}), 3$ years $(\mathrm{G}), 5$ years $(\mathrm{H})$, and 8.4 years $(\mathrm{I})$ after radiotherapy. 
Six months later, the patient revisited the outpatient clinic and was examined by another liver dynamic CT (Fig. 1A). The recurrent tumor in segment 3 had increased up to $11 \mathrm{~cm}$ in size, and an additional $1.7 \mathrm{~cm}$ recurrent HCC in segment 6 was also observed. Through discussion with the multidisciplinary liver cancer team, TACE was performed for the two recurrent HCCs as the first salvage treatment. One month after the first TACE, compact uptake of iodized oil was observed in a small HCC in segment 6, but partial iodized oil uptake in the recurrent HCC in segment 3. After the second TACE (Fig. 1B), external beam radiotherapy was performed for the recurrent HCC in segment 3. The target volume was defined as the recurrent HCC, including both viable and iodized oil uptake area, with additional margin for respiratory motion and set-up errors (Fig. 1C). A total dose of $30 \mathrm{~Gy}$ in 12 fractions (equivalent dose in 2 Gy fractions [EQD2], $\alpha / \beta=10: 31.2 \mathrm{~Gy})$ was delivered with a respiratory gated three-dimensional conformal radiotherapy (3D-CRT) technique using a Real-time Position Management gating system (Varian Medical Systems, Palo Alto, CA, USA). The patient underwent three rounds of additional TACE after radiotherapy. No definitive viable HCC was observed in the liver during the follow-up period (Fig. 1D-H).

At 16 months after completion of radiotherapy for the
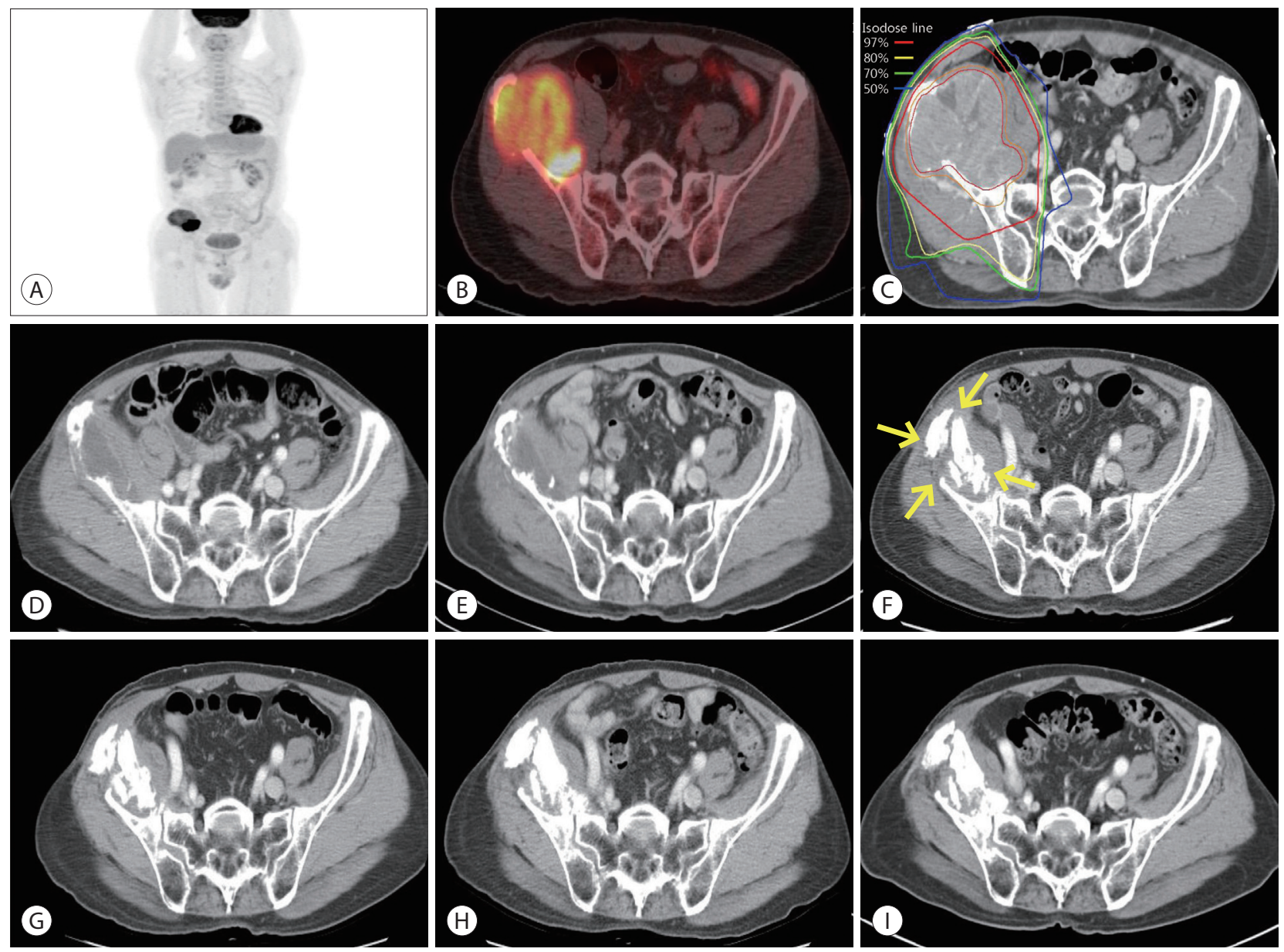

Figure 2. (A, B) Positron emission tomography-computed tomography scan showing a huge osteolytic lesion with maximum standardized uptake value of 11.2 in the right iliac bone. (C) Iso-dose lines of 3-dimensional conformal radiotherapy for the right iliac bone mass on the planning CT. Total dose (60 Gy in 24 fractions) was prescribed with $97 \%$ iso-dose line. (D) Follow-up CT at 3 months after radiotherapy showed a marked decreasing in the enhancing mass. (E) Additional shrinkage of the tumor was observed at 1-year follow-up CT. (F) Two years after radiotherapy, pathologic fractures at the site of bone destruction by the metastatic tumor in the right iliac bone (yellow arrows) were observed. No recurrence was observed on right iliac bone at 3 years $(\mathrm{G}), 5$ years $(\mathrm{H})$, or 6.8 years $(\mathrm{I})$ after radiotherapy. 
HCC in segment 3, the patient complained of pain in the right pelvis. Serum levels of AFP and protein induced by vitamin $\mathrm{K}$ absence or antagonist II (PIVKA-II) had increased to $187.8 \mathrm{ng} / \mathrm{mL}$ and $5,658 \mathrm{mAU} / \mathrm{mL}$, respectively. On a positron emission tomography-CT (PET-CT), a substantial osteolytic lesion showing a heterogenous hypermetabolic mass (maximum standardized uptake value [SUV]: 11.2) was observed in the right iliac bone (Fig. 2A, B). As this is a solitary extrahepatic metastasis without intrahepatic recurrence, high-dose radiotherapy was planned for this metastatic lesion after discussion with the multidisciplinary liver cancer team. A total of $60 \mathrm{~Gy}$ in 24 fractions (EQD2: $62.5 \mathrm{~Gy}$ ) was delivered in the right iliac bone mass using the 3D-CRT technique
(Fig. 2C). The pain was no longer present at 3 months after completion of radiotherapy and a markedly decreased enhancing mass was observed on the follow-up CT (Fig. 2D). Serum AFP and PIVKA-II levels had declined; they were within normal limits $(2.3 \mathrm{ng} / \mathrm{mL}$ and $17 \mathrm{mAU} / \mathrm{mL}$, respectively) 3 months after radiotherapy. Pathologic fractures at the site of bone destruction by the metastatic tumor in the right iliac bone with shrinkage of the tumor was observed on the follow-up CT at 2 years after radiotherapy (Fig. 2E, F); however, the patient was able to walk without any pain or claudication. No recurrence was observed in the right iliac bone during the follow-up period (Fig. 2G, H).

At 3 years and 6 months after radiotherapy for the HCC in
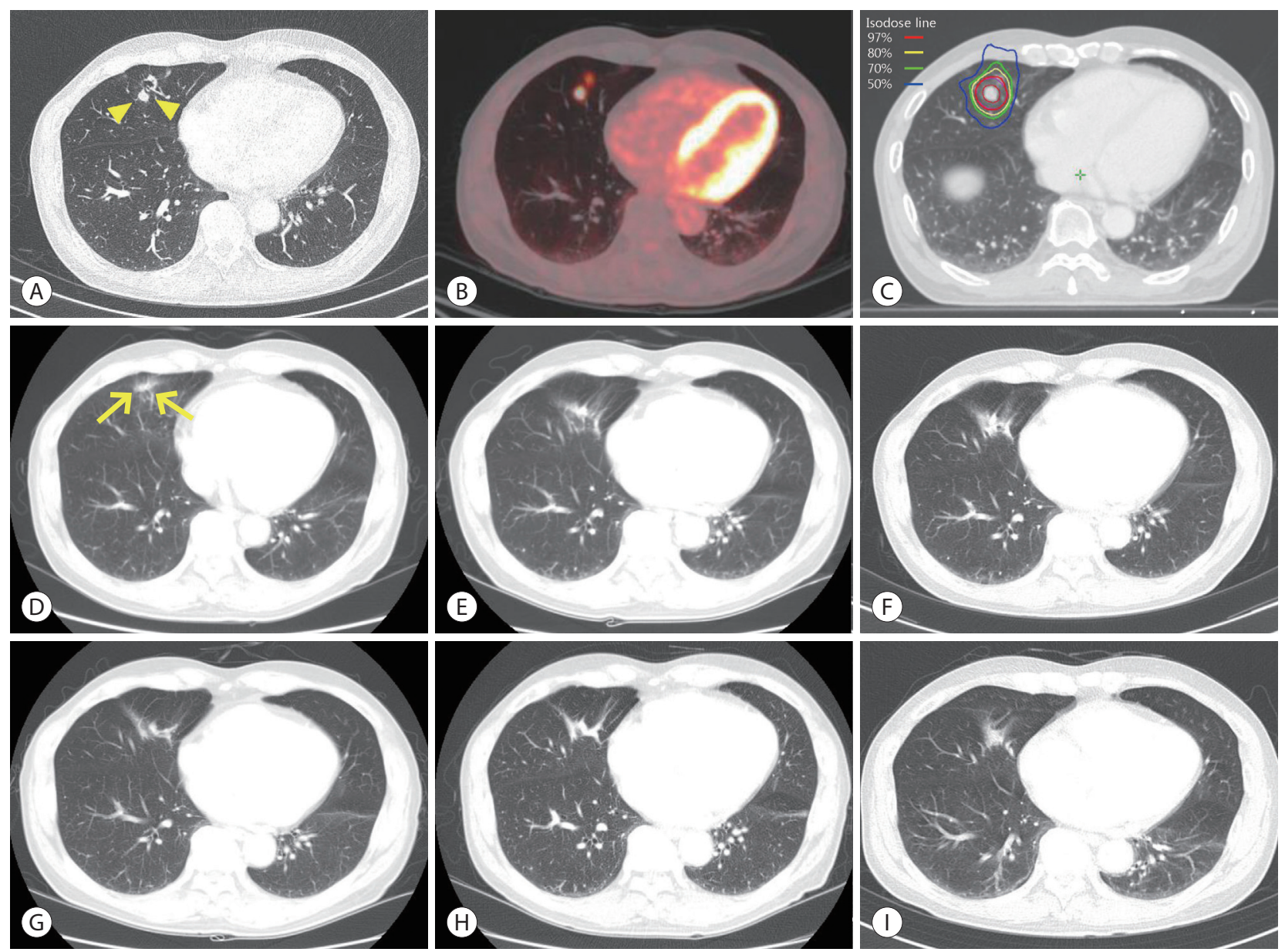

Figure 3. Chest computed tomography (CT) (A) and positron emission tomography-CT (B) scans showing a hypermetabolic metastatic nodule with a maximum standardized uptake value of 11.8 (yellow arrowheads) in the right middle lobe. (C) Iso-dose lines of stereotactic body radiotherapy for lung metastasis on the planning CT. Total dose (60 Gy in 4 fractions) was prescribed with $97 \%$ iso-dose line. (D) After 3 months of stereotactic body radiotherapy, a focal radiation pneumonitis (yellow arrows) without a viable tumor was found. Radiation induced fibrotic changes without recurrence were observed at 1 year $(\mathrm{E}), 2$ years $(\mathrm{F}), 3$ years $(\mathrm{G}), 4$ years $(\mathrm{H})$, and 5 years $(\mathrm{I})$ after radiotherapy. 
segment 3 of the liver, a lung nodule was detected in the right middle lobe on a follow-up liver dynamic CT (Fig. 3A). Chest CT and PET-CT, performed to confirm the metastasis, revealed a single, hypermetabolic lesion measuring $1 \mathrm{~cm}$ (maximum SUV: 11.8) (Fig. 3B). Tumor markers were not elevated at this time (AFP: $2 \mathrm{ng} / \mathrm{mL}$, PIVKA-II: $19 \mathrm{mAU} / \mathrm{mL}$ ). Stereotactic body radiotherapy (SBRT) of $60 \mathrm{~Gy}$ in 4 fractions (EQD2: $125 \mathrm{~Gy}$ ) was performed for this right middle lobe nodule (Fig. 3C) using volumetric-modulated arc therapy technique. After 3 months of SBRT, a focal radiation pneumonitis without viable tumor was found on a chest CT scan (Fig. 3D). During this follow-up period, a fibrotic change without recurrence, induced by radiation, was observed (Fig. 3E-H). All radiotherapies were delivered with linear accelerators (Varian Medical Systems) and each radiation dose was determined based on the guidelines for organs at risk including the normal liver, stomach, duodenum, large bowel, lung, or spinal cord. ${ }^{15-17}$

By the last follow-up examinations (August 27, 2019), no recurrences were observed at any of the locations, including intrahepatic region (Fig. 1I), right pelvic bone (Fig. 2I), right middle lobe nodule (Fig. 3I). Fig. 4 summarizes the treatments and the trends of AFP levels during the 13 years after the initial diagnosis of HCC.

\section{DISCUSSION}

The diagnosis of an unresectable huge HCC shows a poor prognosis as tumor size is an important prognostic factor for survival outcomes in patients with HCC. ${ }^{4,18}$ A multi-modality approach could be considered for better clinical outcomes in this clinical situation, however, there has been no clear evidence supporting the use of combined treatment in patients with huge HCC. Complete uptake of iodized oil is not usually observed even after repeated TACE for huge HCC; ${ }^{19-22}$ therefore, radiotherapy for residual viable HCC after incomplete TACE can be an effective treatment option. ${ }^{13,19,21,23-27}$ Table 1 summarizes the literature on combined TACE and radiotherapy in patients with large HCC $(\geq 5 \mathrm{~cm})$. In the present case, we performed combined TACE (a total of

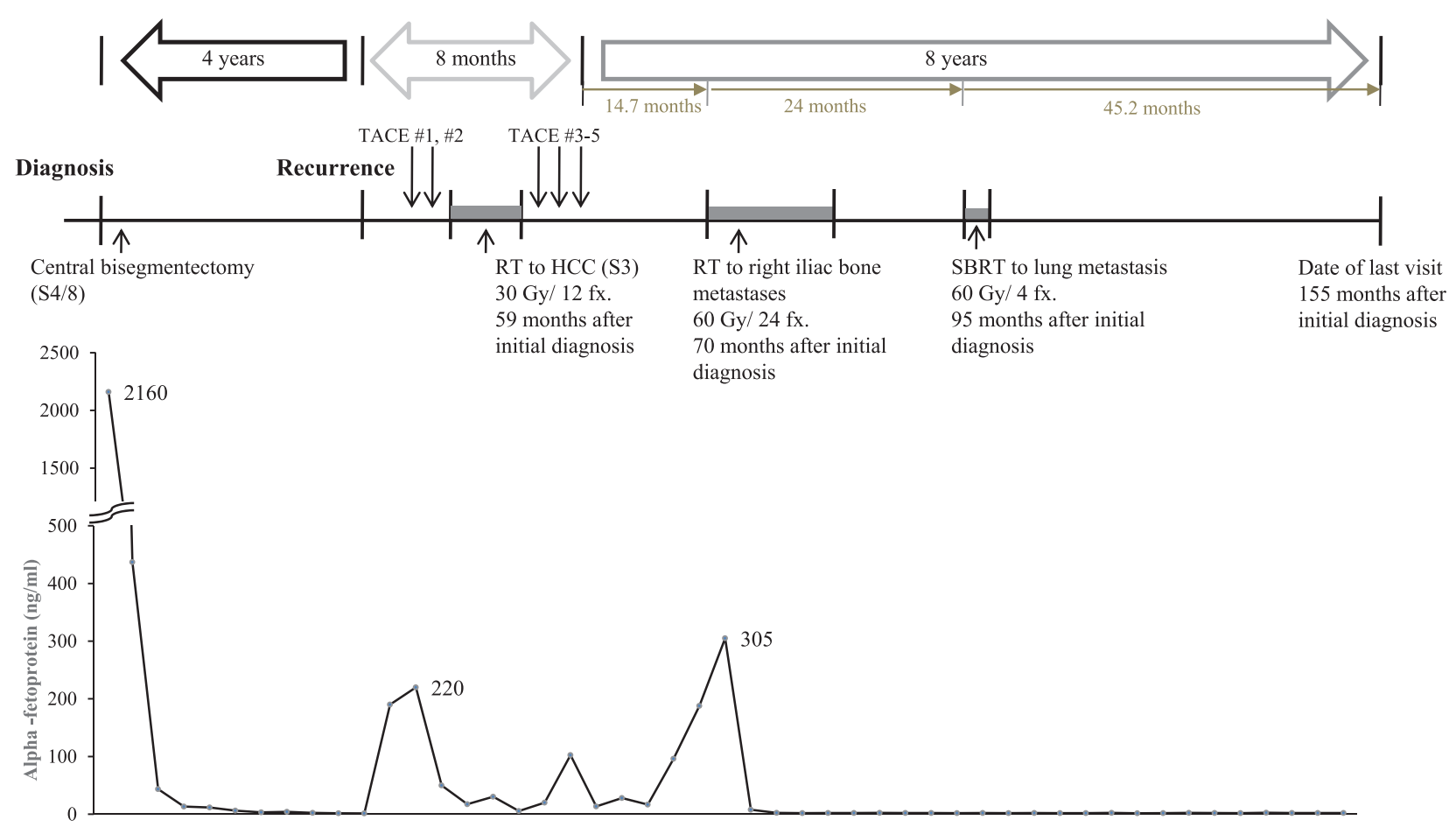

Figure 4. Summary of treatments with the trends of alpha-fetoprotein levels from the initial diagnosis to the last follow-up. TACE, transarterial chemoembolization; RT, radiotherapy; HCC, hepatocellular carcinoma; SBRT, stereotactic body radiotherapy. 
5 times) and radiotherapy for a recurrent HCC measuring 11 $\mathrm{cm}$. Although a high dose could not be prescribed owing to the proximity of the radiosensitive gastrointestinal organs, long-term local tumor control was achieved over the 8 years of follow-up.

The incompletely responding tumor burden in the liver can also be a source of extrahepatic metastasis. The bone is the most frequent metastatic site from HCC, followed by the lung and lymph nodes. ${ }^{28,29}$ In the present case, extrahepatic metastases occurred in the right iliac bone and the lung during the follow-up period. Bone metastasis from HCC typically show a soft tissue mass formation with osteolytic bone changes. Symptoms related with local mass effects can hinder the patients' quality of life (QoL). ${ }^{30-32}$ There have been multiple studies investigating the role of palliative radiotherapy as well as the consideration of higher radiation dose prescriptions for an improved palliative effect in patients with bone metastasis from HCC. ${ }^{31,32}$ In our case, the iliac bone metastasis with a large soft tissue mass was controlled well after a high dose (60 Gy) of radiotherapy over the long-term followup period. Although pathologic fractures occurred at the site of bone destruction by metastatic tumor, radiotherapy was able to maintain the patient's QoL without pain or difficulty in walking.

SBRT is an established treatment option for early-stage lung cancer. ${ }^{33,34}$ In addition, SBRT has also been considered an ablative treatment option for primary or recurrent HCC when curative treatments cannot be safely performed. ${ }^{35,36}$ With these promising clinical outcomes, SBRT can also be used as an ablative treatment for pulmonary oligometastasis from HCC. Although there have been few reports discussing the use of SBRT for lung metastasis from HCC, a study of SBRT for lung metastases from colorectal cancer reported very promising local control rates of $88.7 \%$ and $70.6 \%$ at 1 and 3-years, respectively. ${ }^{37}$ In the current case, a small pulmonary metastasis was no longer present at 3 months after SBRT and did not show recurrence on the follow-up CT scans. Therefore, further studies could reveal the potential role of SBRT for lung metastases from HCC in the future. According to the follow-up results of this patient, the metastatic tumor burden was limited in number and organ (socalled oligometastasis) after the primary site was well controlled. The oligometastatic state is considered an intermediate state of tumor spread showing a more indolent disease course. Metastasis-directed therapies for oligometastasis can be effective and promising approaches, ${ }^{38,39}$ as seen in this patient.

Table 1. Summary of the results of combined transarterial chemoembolization and radiotherapy in large $(\geq 5 \mathrm{~cm})$ hepatocellular carcinomas

\begin{tabular}{|c|c|c|c|c|c|c|c|c|c|c|}
\hline $\begin{array}{r}\text { Author } \\
\text { (year) }\end{array}$ & Design & Cases & $\begin{array}{c}\text { Size } \\
\text { (median, } \\
\mathrm{cm} \text { ) }\end{array}$ & $\begin{array}{c}\text { Vascular } \\
\text { invasion } \\
(\%)\end{array}$ & $\begin{array}{l}\text { Total dose } \\
\text { (median, } \\
\text { Gy) }\end{array}$ & $\begin{array}{l}\text { Fraction } \\
\text { size (Gy) }\end{array}$ & ORR (\%) & DCR (\%) & $\begin{array}{c}\text { Median OS } \\
\text { (months) }\end{array}$ & $\begin{array}{c}\text { 2-year OS } \\
\text { (\%) }\end{array}$ \\
\hline $\begin{array}{c}\text { Guo et al. }{ }^{13} \\
(2003)\end{array}$ & Retrospective & 76 & $\geq 5$ & 24.7 & $30-50$ & $1.8-2$ & 47.4 & 86.9 & N/A & $\begin{array}{c}19.3 \\
\text { (5-year OS) }\end{array}$ \\
\hline $\begin{array}{l}\text { Shirai et al. }{ }^{23} \\
(2010)\end{array}$ & Prospective & 19 & 10.1 & 100 & 45 & 2.5 & 36.8 & 89.4 & 10.3 & 23.7 \\
\hline $\begin{array}{c}\text { Xu et al. } \\
\text { (2011) }\end{array}$ & Retrospective & 140 & 7.8 & 19.2 & 44 & 2.0 & 19.2 & 88.5 & 18 & $\begin{array}{c}13 \\
\text { (5-year OS) }\end{array}$ \\
\hline $\begin{array}{l}\text { Yoon et al. }{ }^{25} \\
(2012)\end{array}$ & Retrospective & 412 & 9.5 & 100 & 40 & $2.0-5.0$ & 28.1 & 36.4 & 10.6 & 22.8 \\
\hline $\begin{array}{c}\text { Kim et al. } \\
\text { (2014) }\end{array}$ & Retrospective & 35 & 12.1 & 37.1 & 45 & $1.8-2.9$ & $N / A$ & 97.1 & 15.3 & 23.5 \\
\hline $\begin{array}{c}\text { Yu et al. } \\
\text { (2017) }\end{array}$ & Prospective & 69 & 7.2 & 100 & $47.25 \mathrm{~Gy}_{10}$ & $2.5-4.5$ & 69.6 & 85.0 & N/A & 62.9 \\
\hline $\begin{array}{l}\text { Yoon et al. } \\
\text { (2018) }\end{array}$ & Prospective & 45 & 9.8 & 100 & 45 & $2.5-3.0$ & 33.3 & 55.5 & 13.7 & $\begin{array}{c}55.4 \\
\text { (1-year OS) }\end{array}$ \\
\hline
\end{tabular}

ORR, objective response rate (complete response+partial response); DCR, disease control rate (complete response+partial response+stable disease); OS, overall survival; N/A, not available. 
In summary, combined TACE and external beam radiotherapy yielded excellent long-term local tumor control in a patient with recurrent, huge HCC. Despite the extrahepatic recurrences in the bone and lung, salvage radiotherapy is highly effective and allows this patient to maintain his QoL.

\section{Conflicts of Interest}

The authors have no conflicts of interest to disclose.

\section{REFERENCES}

1. Bruix J, Reig M, Sherman M. Evidence-based diagnosis, staging, and treatment of patients with hepatocellular carcinoma. Gastroenterology 2016;150:835-853.

2. Goh BK, Kam JH, Lee SY, Chan CY, Allen JC, Jeyaraj P, et al. Significance of neutrophil-to-lymphocyte ratio, platelet-to-lymphocyte ratio and prognostic nutrition index as preoperative predictors of early mortality after liver resection for huge $(\geq 10 \mathrm{~cm})$ hepatocellular carcinoma. J Surg Oncol 2016;113:621-627.

3. Hwang S, Lee YJ, Kim KH, Ahn CS, Moon DB, Ha TY, et al. Longterm outcome after resection of huge hepatocellular carcinoma $\geq 10 \mathrm{~cm}$ : single-institution experience with 471 patients. World J Surg 2015;39:2519-2528.

4. Lee SG, Hwang S, Jung JP, Lee YJ, Kim KH, Ahn CS. Outcome of patients with huge hepatocellular carcinoma after primary resection and treatment of recurrent lesions. Br J Surg 2007;94:320326.

5. Jia C, Weng J, Qin Q, Chen Y, Huang X, Fu Y. Anatomic trisegmentectomy: an alternative treatment for huge or multiple hepatocellular carcinoma of right liver. Biomed Pharmacother 2017;88:684688.

6. Yamashita Y, Taketomi A, Shirabe K, Aishima S, Tsuijita E, Morita $K$, et al. Outcomes of hepatic resection for huge hepatocellular carcinoma ( $\geq 10 \mathrm{~cm}$ in diameter). J Surg Oncol 2011;104:292-298.

7. Jin YJ, Lee JW, Choi YJ, Chung HJ, Kim YS, Lee KY, et al. Surgery versus transarterial chemoembolization for solitary large hepatocellular carcinoma of BCLC stage A. J Gastrointest Surg 2014;18:555-561.

8. Min YW, Lee JH, Gwak GY, Paik YH, Lee JH, Rhee PL, et al. Longterm survival after surgical resection for huge hepatocellular carcinoma: comparison with transarterial chemoembolization after propensity score matching. J Gastroenterol Hepatol 2014;29:10431048.

9. Mok KT, Wang BW, Lo GH, Liang HL, Liu SI, Chou NH, et al. Multimodality management of hepatocellular carcinoma larger than 10 cm. J Am Coll Surg 2003;197:730-738.
10. Han HJ, Kim MS, Cha J, Choi JS, Han KH, Seong J. Multimodality treatment with radiotherapy for huge hepatocellular carcinoma. Oncology 2014;87 Suppl 1:82-89.

11. Honda Y, Kimura T, Aikata H, Kobayashi T, Fukuhara T, Masaki K, et al. Stereotactic body radiation therapy combined with transcatheter arterial chemoembolization for small hepatocellular carcinoma. J Gastroenterol Hepatol 2013;28:530-536.

12. Zhu SL, Zhong JH, Ke Y, Ma L, You XM, Li LQ. Efficacy of hepatic resection vs transarterial chemoembolization for solitary huge hepatocellular carcinoma. World J Gastroenterol 2015;21:9630-9637.

13. Guo WJ, Yu EX, Liu LM, Li J, Chen Z, Lin JH, et al. Comparison between chemoembolization combined with radiotherapy and chemoembolization alone for large hepatocellular carcinoma. World J Gastroenterol 2003;9:1697-1701.

14. Yoon SM, Ryoo BY, Lee SJ, Kim JH, Shin JH, An JH, et al. Efficacy and safety of transarterial chemoembolization plus external beam radiotherapy vs sorafenib in hepatocellular carcinoma with macroscopic vascular invasion: a randomized clinical trial. JAMA Oncol 2018;4:661-669.

15. Pan CC, Kavanagh BD, Dawson LA, Li XA, Das SK, Miften M, et al. Radiation-associated liver injury. Int J Radiat Oncol Biol Phys 2010;76:S94-S100.

16. Marks LB, Yorke ED, Jackson A, Ten Haken RK, Constine LS, Eisbruch $A$, et al. Use of normal tissue complication probability models in the clinic. Int J Radiat Oncol Biol Phys 2010;76(3 Suppl):S10S19.

17. Benedict SH, Yenice KM, Followill D, Galvin JM, Hinson W, Kavanagh $B$, et al. Stereotactic body radiation therapy: the report of AAPM Task Group 101. Med Phys 2010;37:4078-4101.

18. Wakayama K, Kamiyama T, Yokoo H, Orimo T, Shimada S, Einama T, et al. Huge hepatocellular carcinoma greater than $10 \mathrm{~cm}$ in diameter worsens prognosis by causing distant recurrence after curative resection. J Surg Oncol 2017;115:324-329.

19. Oh D, Lim DH, Park HC, Paik SW, Koh KC, Lee JH, et al. Early three-dimensional conformal radiotherapy for patients with unresectable hepatocellular carcinoma after incomplete transcatheter arterial chemoembolization: a prospective evaluation of efficacy and toxicity. Am J Clin Oncol 2010;33:370-375.

20. Chen LC, Chiou WY, Lin HY, Lee MS, Lo YC, Huang LW, et al. Comparing stereotactic ablative radiotherapy (SABR) versus retrans-catheter arterial chemoembolization (re-TACE) for hepatocellular carcinoma patients who had incomplete response after initial TACE (TASABR): a randomized controlled trial. BMC Cancer 2019;19:275.

21. Kang JK, Kim MS, Cho CK, Yang KM, Yoo HJ, Kim JH, et al. Stereotactic body radiation therapy for inoperable hepatocellular carcinoma as a local salvage treatment after incomplete transarterial chemoembolization. Cancer 2012;118:5424-5431. 
22. Paik EK, Kim MS, Jang WI, Seo YS, Cho CK, Yoo HJ, et al. Benefits of stereotactic ablative radiotherapy combined with incomplete transcatheter arterial chemoembolization in hepatocellular carcinoma. Radiat Oncol 2016;11:22.

23. Shirai S, Sato M, Suwa K, Kishi K, Shimono C, Sonomura T, et al. Feasibility and efficacy of single photon emission computed tomography-based three-dimensional conformal radiotherapy for hepatocellular carcinoma $8 \mathrm{~cm}$ or more with portal vein tumor thrombus in combination with transcatheter arterial chemoembolization. Int J Radiat Oncol Biol Phys 2010;76:1037-1044.

24. Xu LT, Zhou ZH, Lin JH, Chen Z, Wang K, Wang P, et al. Clinical study of transarterial chemoembolization combined with 3-dimensional conformal radiotherapy for hepatocellular carcinoma. Eur J Surg Oncol 2011;37:245-251.

25. Yoon SM, Lim YS, Won HJ, Kim JH, Kim KM, Lee HC, et al. Radiotherapy plus transarterial chemoembolization for hepatocellular carcinoma invading the portal vein: long-term patient outcomes. Int J Radiat Oncol Biol Phys 2012;82:2004-2011.

26. Kim KH, Kim MS, Chang JS, Han KH, Kim DY, Seong J. Therapeutic benefit of radiotherapy in huge $(\geq 10 \mathrm{~cm})$ unresectable hepatocelIular carcinoma. Liver Int 2014;34:784-794.

27. Yu Jl, Park HC, Jung SH, Choi C, Shin SW, Cho SK, et al. Combination treatment with transarterial chemoembolization, radiotherapy, and hyperthermia (CERT) for hepatocellular carcinoma with portal vein tumor thrombosis: final results of a prospective phase II trial. Oncotarget 2017:8:52651-52664.

28. Ikai I, Arii S, Okazaki M, Okita K, Omata M, Kojiro M, et al. Report of the 17th Nationwide Follow-up Survey of Primary Liver Cancer in Japan. Hepatol Res 2007;37:676-691.

29. Harding JJ, Abu-Zeinah G, Chou JF, Owen DH, Ly M, Lowery MA, et al. Frequency, morbidity, and mortality of bone metastases in advanced hepatocellular carcinoma. J Natl Compr Canc Netw 2018;16:50-58.

30. He J, Zeng ZC, Tang ZY, Fan J, Zhou J, Zeng MS, et al. Clinical features and prognostic factors in patients with bone metastases from hepatocellular carcinoma receiving external beam radiotherapy. Cancer 2009;115:2710-2720.

31. Hayashi S, Tanaka H, Hoshi H. Palliative external-beam radiotherapy for bone metastases from hepatocellular carcinoma. World J Hepatol 2014;6:923-929.

32. Jung IH, Yoon SM, Kwak J, Park JH, Song SY, Lee SW, et al. High-dose radiotherapy is associated with better local control of bone metastasis from hepatocellular carcinoma. Oncotarget 2017:8:15182-15192.

33. Maquilan G, Timmerman R. Stereotactic body radiation therapy for early-stage lung cancer. Cancer J 2016;22:274-279.

34. Roesch J, Andratschke N, Guckenberger M. SBRT in operable early stage lung cancer patients. Transl Lung Cancer Res 2014;3:212224.

35. Sapir E, Tao Y, Schipper MJ, Bazzi L, Novelli PM, Devlin P, et al. Stereotactic body radiation therapy as an alternative to transarterial chemoembolization for hepatocellular carcinoma. Int J Radiat Oncol Biol Phys 2018;100:122-130.

36. Wahl DR, Stenmark MH, Tao Y, Pollom EL, Caoili EM, Lawrence TS, et al. Outcomes after stereotactic body radiotherapy or radiofrequency ablation for hepatocellular carcinoma. J Clin Oncol 2016;34:452-459.

37. Jung J, Song SY, Kim JH, Yu CS, Kim JC, Kim TW, et al. Clinical efficacy of stereotactic ablative radiotherapy for lung metastases arising from colorectal cancer. Radiat Oncol 2015;10:238.

38. Ost P, Bossi A, Decaestecker K, De Meerleer G, Giannarini G, Karnes RJ, et al. Metastasis-directed therapy of regional and distant recurrences after curative treatment of prostate cancer: a systematic review of the literature. Eur Urol 2015;67:852-863.

39. Hong JC, Ayala-Peacock DN, Lee J, Blackstock AW, Okunieff P, Sung MW, et al. Classification for long-term survival in oligometastatic patients treated with ablative radiotherapy: a multiinstitutional pooled analysis. PLoS One 2018;13:e0195149. 